\title{
Pirâmide Multiplicativa: um jogo sério para a memorização da tabuada
}

\author{
Joelson Vitor Rolino ${ }^{1}$, Dais Capucho Afini ${ }^{1}$, Gustavo Borges Vieira ${ }^{1}$ \\ ${ }^{1}$ Instituto de Ciências Exatas - Universidade Federal de Alfenas (UNIFAL-MG) \\ Alfenas - MG - Brasil \\ joelsonrolino@hotmail, daisafini@gmail.com, gborgesvieira@gmail.com
}

\begin{abstract}
This article presents the development of a digital educational serious game that aims to be an alternative to the teaching and learning of multiplication tables through the use of computational tools. The game was explored by Math Teachers in formation and valued of the agreement with the methodology Retain .

Resumo. Este artigo apresenta o desenvolvimento de um jogo sério educacional digital que tem o objetivo de ser uma alternativa para o ensino e aprendizagem da tabuada através da utilização de ferramentas computacionais. $O$ jogo foi explorado por professores de matemática em formação e avaliado de acordo com a metodologia RETAIN.
\end{abstract}

\section{Introdução}

Uma das atividades realizadas no primeiro ciclo do ensino fundamental é a memorização da tabuada por meio da chamada oral, na qual o professor perguntando aos alunos algumas multiplicações e estes respondem corretamente os resultados. Essa prática tem como finalidade proporcionar a memorização da tabuada para facilitar os cálculos matemáticos, uma vez que a aprendizagem da matemática se resume ao ensino de aritmética, em especial ao conhecimento de tabuada e resolução de "continhas", Carvalho e Gonçalves (2003).

No entanto, diferente do que acontece no primeiro ciclo do ensino fundamental o professor de matemática de $6^{\circ}$ ao $9^{\circ}$ anos não mais "toma a tabuada", resultando no esquecimento por parte dos estudantes, já que esta foi memorizada ao invés de ser compreendida. Assim, os estudantes recorrem a aparelhos eletrônicos como calculadoras e celulares para obtenção dos resultados das multiplicações.

Nesse contexto, as aulas do professor de matemática é fundamentada no paradigma do exercício, ou seja, primeiro o professor explica a definição e apresenta algumas técnicas matemáticas e depois os alunos resolvem exercícios, existindo uma variação nesse procedimento podendo o professor ministrar uma aula totalmente expositiva ou os alunos passarem toda a aula resolvendo exercícios. De qualquer forma, a aula se resume a resolução de exercícios geralmente selecionados no livro didático, Skovsmose (2000). O que confirma a dificuldade apresentada por educandos do ensino fundamental e médio na resolução de problemas envolvendo operações elementares, principalmente multiplicação e divisão. Esta deficiência pode inibir a aprendizagem de novos conteúdos específicos de Matemática e até causar desmotivação com as aulas, mas o professor se vê impossibilitado de retomar certos conhecimentos considerados básicos porque o tempo é curto sendo necessário cumprir o cronograma escolar. 
Assim, o objetivo deste artigo é apresentar um jogo sério denominado Pirâmide Multiplicativa que foi avaliado e validado por licenciandos em matemática de uma Universidade Federal por meio da metodologia RETAIN. O jogo Pirâmide Multiplicativa expõe algumas operações de multiplicação e seus respectivos resultados em forma de pirâmide, tendo como finalidade auxiliar na memorização da tabuada, estimular a rapidez do raciocínio matemático, o cálculo mental e a memória visual. Além disso, o jogador pode refletir sobre seus erros e desenvolver estratégias de verificação dos resultados. Como afirma Moita, Luciano e Costa (2012, p. 3080)

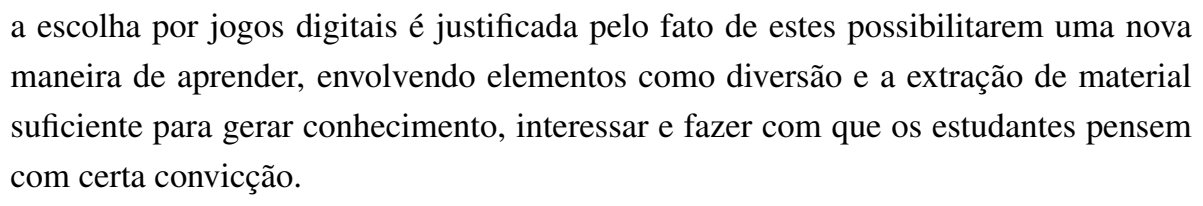
maneira de aprender, envolvendo elementos como diversão e a extração de material suficiente para gerar conhecimento, interessar e fazer com que os estudantes pensem com certa convicção.

Segundo Borin (2004), ao se introduzir jogos nas aulas de matemática é possível amenizar bloqueios observados em alunos que temem a matéria e se sentem incapacitados para aprendê-la. E de acordo com Kamii (2003), os alunos devem compreender a multiplicação, mas também desenvolver a rapidez de cálculo e, para isso, propõe que em vez de os alunos responderem a diversas questões repetitivas de manuais escolares, desenvolvam a memorização da tabuada através de jogos.

Dessa forma, as próximas seções apresentam argumentos em defesa da utilização de jogos no processo de ensino-aprendizagem de matemática, descreve a metodologia usada para a realização do trabalho, retrata a construção do jogo Pirâmide Multiplicativa, apresenta os resultados e encerra fazendo algumas considerações finais.

\section{Revisão de Literatura}

Segundo Michael e Chen (2006), um jogo sério tem como principal objetivo a aprendizagem e não a distração. De acordo com Moura e Viamonte (2009), os jogos com fins pedagógicos auxiliam no processo de ensino-aprendizagem, a medida que os alunos assumem papel ativo e participam das transformações que ocorrem no jogo, na busca de uma solução ou na tentativa de alcançar os objetivos propostos.

De acordo com Medeiros e Schimiguel (2012), as crianças têm acesso a tecnologia desde muito cedo e se familiarizam com jogos que vão chamar sua atenção. Desse modo, o uso de jogos na educação além de ser fonte de diversão pode ser utilizado como instrumento de desenvolvimento, pois auxilia no desenvolvimento da linguagem, da criatividade e do raciocínio lógico dedutivo.

Os autores afirmam que um profissional capaz de se reinventar diante das necessidades vem se tornando mais desejado e se destaca perante um profissional que não têm atitudes de mudança. Nesse sentido, o professor deve saber escolher qual a melhor estratégia e o melhor jogo para utilizar em sua aula. Um professor que é apenas transmissor de conhecimento pode não conseguir mais atender os novos desafios trazidos por seus aprendizes nativos digitais.

Os jogos digitais contribuem para a concentração do aprendiz, respeita suas individualidades, propicia um ambiente prazeroso e sem riscos. Além de lhes assegurar seu próprio ritmo de aprendizagem. Visto que, durante a execução do jogo o aprendiz toma suas próprias decisões e testa seus conhecimentos. 
Medeiros e Schimiguel (2012) ressaltam que os jogos são instrumentos que propiciam a aprendizagem significativa de conceitos quando possuem uma finalidade préestabelecida. Ou seja, os jogos só têm sentido quando todas suas potencialidades são exploradas de forma crítica, a fim de que o aluno possa estabelecer relações entre o jogo e o que foi assimilado durante as aulas. Vale salientar que o jogo causa alguns transtornos como agitação e conversa paralela entre os alunos. Dessa forma, o professor deve intervir como mediador do conhecimento sabendo de antemão o funcionamento do jogo, conduzindo as discussões durante a execução do mesmo e ajudando no trabalho em equipe.

Medeiros e Schimiguel (2012), em seu trabalho utiliza duas metodologias para avaliar a qualidade dos jogos digitais. A primeira metodologia é a LORI (Learning Object Review Instrument) que compreende nove questionamentos dentre os quais podemos citar a qualidade do conteúdo, alinhamento do objetivo de aprendizagem e motivação. Essa metodologia não consegue avaliar de forma ampla um jogo digital educacional deixando alguns critérios ainda muito vagos.

Dessa forma, outra metodologia de avaliação de jogos eletrônicos é a GameFlow que avalia questões como concentração, desafio, objetivos claros, interação social, entre outros aspectos. Sendo uma avaliação mais eficaz tendo em vista como é prazeroso o jogo para o jogador. Assim, os autores a partir das metodologias LORI e GameFlow criam uma metodologia para avaliar o jogo eletrônico Stop, mesclando objetivos das duas metodologias como qualidade do conteúdo, motivação e objetivos claros.

Segundo Cardoso, Giraldello e Batista (2013), a metodologia baseada em jogos objetiva estimular a interação, explorar, produzir e exercitar o conhecimento. No entanto, ressaltam que o uso de jogos durante as aulas de matemática requer dedicação por parte dos educadores, pois é preciso pesquisar, definir os objetivos e os conteúdos a serem explorados por meio dos jogos. Visto que de acordo com Cardoso, Giraldello e Batista (2013, p. 378), “ "o jogo pelo jogo”, sem direcionamento para o aprendizado e sem que seu potencial seja explorado de forma adequada, pode se transformar em uma atividade fracassada do ponto de vista do ensino-aprendizagem'.

Diante do exposto nota-se a importância da utilização intencional e planejada de jogos na sala de aula como uma ferramenta de auxílio no processo de ensinoaprendizagem. Já que o jogo cria um ambiente desafiador ao aluno instigando a tomada de decisões pelos aprendizes de acordo com seus conhecimentos prévios. Segundo Maluta (2007), o jogo inserido na área de Educação Matemática é um fenômeno cultural que foge do cotidiano dos alunos, com espaço e tempo bem definidos, dotado de regras com uma finalidade imperceptível para quem joga.

\section{Metodologia}

O jogo Pirâmide Multiplicativa foi programado no Game Editor que é uma ferramenta com linguagem simples e de fácil compreensão utilizado para o desenvolvimento de jogos. Para a elaboração das peças do jogo foram utilizados os programas computacionais GIMP e PhotoScape que são editores de imagens livres.

O Game Editor possui um pacote para criação de jogos em duas dimensões que utiliza a linguagem de programação $\mathrm{C} / \mathrm{C}++$. O programa apoia o desenvolvimento multiplataforma para iPhone, iPad, Mac OS X, Windows, Linux, Pocket PC, Windows Mobile, Smartphones e GP2X baseados no Windows Mobile. 
O GIMP (GNU Image Manipulation Program) é um programa de código aberto voltado principalmente para criação e edição de imagens. Em menor escala é uma alternativa livre ao programa Adobe Photoshop. O GIMP foi um projeto universitário que amadureceu bastante e hoje alcança expressiva popularidade. Já o programa PhotoScape é um editor de imagem que apresenta como principal característica a facilidade de ser manipulado por iniciantes e também oferece diversos recursos.

Visando a originalidade do jogo Pirâmide Multiplicativa foi realizado um levantamento em sites de busca da rede mundial de computadores através das palavras-chaves Pirâmide Multiplicativa, jogos de multiplicação e multiplication game. Além disso, foi feita uma pesquisa nos anais do Simpósio Brasileiro de Informática na Educação (SBIE) com as palavras-chaves jogos, jogos sérios e jogos de multiplicação.

Para validação do jogo Pirâmide Multiplicativa foram selecionados quinze licenciandos do primeiro ao oitavo período do curso de Licenciatura em Matemática de uma Universidade Federal. O jogo foi apresentado aos licenciandos através de uma lousa interativa para dinamizar a manipulação das peças do jogo.

Após a manipulação do jogo na lousa interativa foi solicitado aos licenciandos que respondessem a um questionário avaliativo com perguntas relacionadas a importância da utilização de jogos digitais nas aulas de matemática e sobre os benefícios da utilização desses jogos para a consolidação de conceitos matemáticos pelos estudantes do segundo ciclo do ensino fundamental.

Para a avaliação do jogo Pirâmide Multiplicativa foi utilizada a metodologia RETAIN. De acordo com os trabalhos de Luciano e Oliveira (2012) e Gunter, Kenny e Vick (2008), a metodologia RETAIN é utilizada para a avaliação de jogos digitais e analisa seis aspectos:

i) Relevância: o jogo deve apresentar o conteúdo abordado de maneira atrativa para que seja significante ao jogador.

ii) Incorporação: o conteúdo de aprendizagem e a ludicidade devem aparecer vinculados um ao outro no jogo.

iii) Transferência: o jogo deve proporcionar ao jogador situações em que ele consiga utilizar seus conhecimentos prévios para manipular o jogo.

iv) Adaptação: o jogador deve apresentar mudanças de comportamento favoráveis a aprendizagem após manipular o jogo.

v) Imersão: o jogo deve ser atrativo e motivar para que o jogador esteja sempre ativo no jogo.

vi) Naturalização: o conhecimento adquirido durante a manipulação do jogo deve ser interiorizado pelo jogador.

\section{Pirâmide Multiplicativa}

Uma das atividades realizadas por bolsistas de iniciação a docência do Programa Institucional de Bolsas de Iniciação à Docência (PIBID) nas escolas parceiras pertencentes à rede pública de ensino é o acompanhamento do professor nas aulas de matemática. Durante esta atividade foi possível diagnosticar que os estudantes do segundo ciclo do ensino fundamental apresentam dificuldades para resolver situações-problemas envolvendo a operação de multiplicação, podendo assim interferir na aprendizagem de conteúdos matemáticos mais complexos. 
O PIBID é destinado à formação de professores e desenvolve atividades didáticas que priorizam a construção do conhecimento por meio de materiais manipuláveis e ferramentas computacionais. Dessa forma, visando amenizar as dificuldades dos estudantes quanto a operação de multiplicação os pesquisadores desenvolveram o jogo Pirâmide Multiplicativa que tem como objetivo a memorização da tabuada.

O jogo Pirâmide Multiplicativa foi idealizado a partir do jogo chinês Mahjong, o qual é muito difundido na cultura ocidental. Segundo Otsuka et al. (2012), o jogo Mahjong consiste em um tabuleiro formado por peças com símbolos orientais. O objetivo do jogo é formar pares com peças iguais no menor tempo possível. A Figura 1 mostra a interface de um jogo Mahjong disponível na internet.

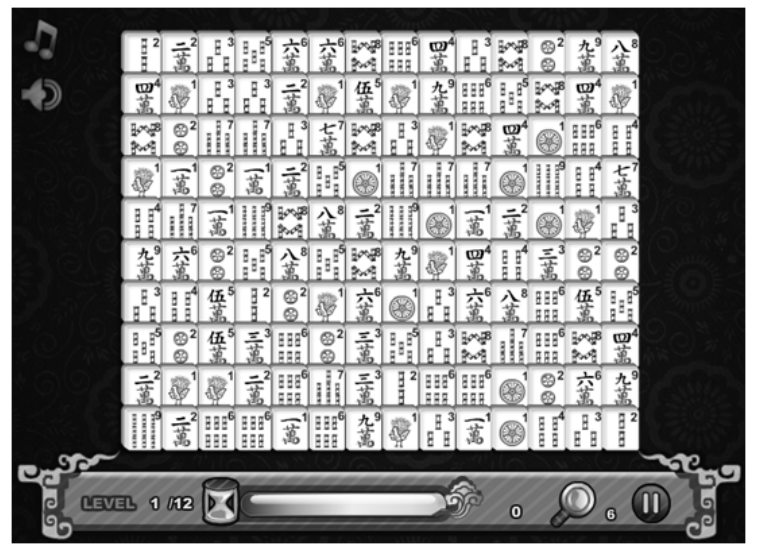

Figure 1. Interface de um jogo Mahjong disponível na internet.

O jogo Pirâmide Multiplicativa é composto por peças dispostas no formato de pirâmide. Ao invés de imagens orientais, as peças contêm operações de multiplicação e seus respectivos resultados. Assim, o jogador deve associar corretamente a operação de multiplicação com o seu respectivo resultado. Cada par formado corretamente desaparece da interface do jogo e corresponde à mil pontos no placar. A medida que os pares vão desaparecendo as peças que antes estavam sobrepostas ficam visíveis. O jogo termina quando todos os pares de peças forem formados. As únicas peças livres para serem associadas são as que estão nas bordas, ou seja, as que possuem apenas três "vizinhos" ao invés de quatro. Os "vizinhos" são as peças que estão localizadas acima, abaixo, à direita ou à esquerda de cada peça.

Quando o jogo Pirâmide Multiplicativa é iniciado, uma tela inicial é apresentada ao jogador, informando quais são as instruções e regras para prosseguir, Figura 2. A dinâmica de seleção das peças segue uma lógica. As peças possuem um contorno preto. Quando pressionadas o contorno fica vermelho indicando que o bloco foi selecionado. Há um cronômetro para marcar o tempo gasto na finalização do jogo. 


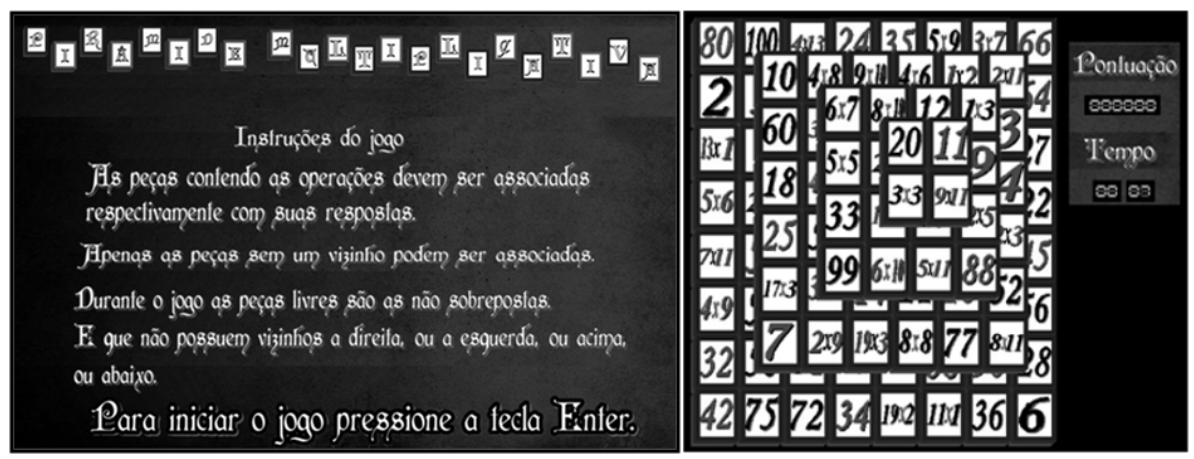

Figure 2. À direita: tela inicial com as instruções do jogo. À esquerda: interface do jogo Pirâmide Multiplicativa.

Para modificar a peça de um jogo Mahjong encontrado na internet foi utilizado o programa computacional GIMP. A Figura 3 mostra o processo de evolução das imagens até se obter a representação final das peças que compõem o jogo Pirâmide Multiplicativa. Inicialmente, foi capturada a imagem de uma peça original de um jogo Mahjong disponível na internet, como representado no passo 1 da Figura 3. Em seguida, o símbolo chinês exibido na peça capturada foi substituído pelas operações de multiplicação e seus respectivos resultados, conforme o passo 2 da Figura 3. Para que a peça representasse um bloco retangular foi preciso colocar em cada peça um efeito de perspectiva disponível no programa computacional PhotoScape, como mostra o passo 3. Por fim, a imagem foi combinada junto com os símbolos numéricos de forma que se tornasse a peça utilizada no jogo Pirâmide Multiplicativa, como representado no passo 4. Para finalizar, as peças foram salvas no formato PNG para que tivessem um fundo transparente e não interferissem no cenário final do jogo.

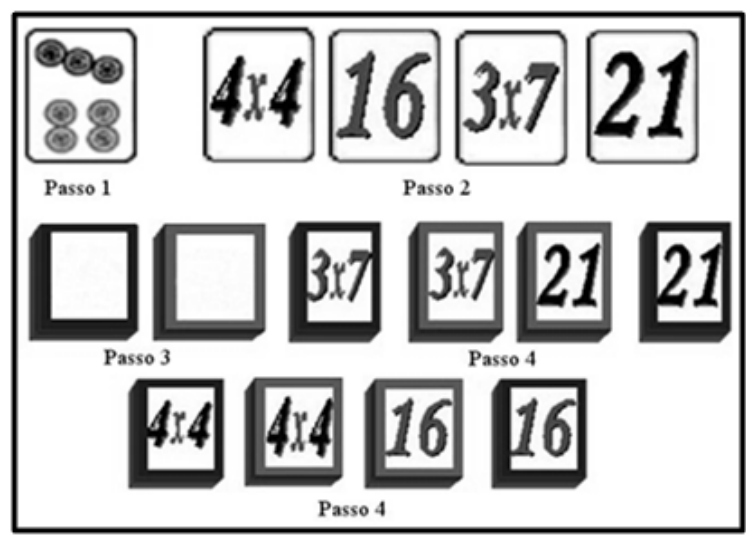

Figure 3. Processo de construção das peças do jogo Pirâmide Multiplicativa.

No programa Game Editor, as peças foram inseridas e programadas individualmente. Para que as peças transmitissem o efeito piramidal as peças dos tabuleiros 2, $3 \mathrm{e}$ 4, representados pelas Figuras 4 à direita e 5, foram deslocadas paralelamente. As peças criadas inicialmente são as do tabuleiro, Figura 4 à esquerda. Em seguida, foram colocados os tabuleiros 2, 3 e 4, um sobre o outro. Quanto à posição as peças foram inseridas da direita para a esquerda e de cima para baixo. A ordem em que aparecem as peças é constante e obedece sempre uma mesma disposição. 


\begin{tabular}{|c|c|c|c|c|c|c|c|c|c|c|c|c|c|}
\hline 80 & 100 & $4 \times 13$ & 24 & 35 & $5 \times 9$ & $3 \times 7$ & 66 \\
\hline 2 & 1 & $10 \times 10$ & $6 \times 9$ & $2 \times 4$ & $4 \times 7$ & 44 & 64 \\
\hline $13 \times 1$ & 0 & $11 \times 6$ & $3 \times 5$ & 48 & $6 \times 8$ & 5 & 27 \\
\hline $5 \times 6$ & $2 \times 7$ & $17 \times 1$ & 49 & 63 & 96 & $4 \times 11$ & 22 \\
\hline $7 \times 11$ & 51 & $7 \times 8$ & $7 \times 9$ & $7 \times 7$ & 15 & 54 & 45 \\
\hline $4 \times 9$ & 57 & $17 \times 2$ & $9 \times 9$ & 81 & 17 & 19 & 56 \\
\hline 32 & 50 & $1 \times 1$ & $1 \times 5$ & $19 \times 1$ & 38 & 90 & 28 \\
\hline 42 & 75 & 72 & 34 & $19 \times 2$ & $11 \times 1$ & 36 & 6 & $3 \times 11$ & $8 \times 9$ & $15 \times 5$ & $0 \times 0$ & 3 \\
\hline 25 & 55 & 8 & $4 \times 5$ & $3 \times 4$ & $5 \times 10$ & 30 & 4 \\
\hline 7 & $17 \times 3$ & $3 \times 9$ & 14 & 21 & $1 \times 7$ & 16 & 52 \\
\hline 7 & $2 \times 9$ & $19 \times 3$ & $8 \times 8$ & 77 & $8 \times 11$ \\
\hline
\end{tabular}

Figure 4. À esquerda: tabuleiro 1. À direita: tabuleiro 2.

\begin{tabular}{|c|c|c|c||c|c|}
\hline $6 \times 7$ & $8 \times 10$ & 12 & $1 \times 3$ & \multicolumn{2}{|c|}{} \\
\hline $5 \times 5$ & $2 \times 2$ & $5 \times 7$ & 9 & 20 & 11 \\
\hline 33 & $12 \times 8$ & 13 & $2 \times 5$ & $3 \times 3$ & $9 \times 11$ \\
\hline 99 & $6 \times 10$ & $5 \times 11$ & 88 & \multicolumn{2}{|c}{} \\
\hline
\end{tabular}

Figure 5. À esquerda: tabuleiro 3. À direita: tabuleiro 4.

\section{Resultados e discussões}

Para produção do jogo Pirâmide Multiplicativa foi realizado um levantamento em sites de busca da rede mundial de computadores objetivando encontrar materiais já existentes sobre o ensino de multiplicação, principalmente jogos digitais. Na primeira pesquisa a palavra-chave de busca foi "Pirâmide Multiplicativa". Nessa pesquisa foram apresentados aproximadamente 337.000 resultados, porém os resultados não foram satisfatórios. Já que na primeira página foi encontrado apenas uma atividade didática impressa com o título da pesquisa e nas próximas nove páginas seguintes também nenhum resultado foi satisfatório.

Na segunda pesquisa, a palavra-chave de busca foi "jogos de multiplicação". A pesquisa resultou em aproximadamente 537.000 resultados. Já na terceira pesquisa, a palavra-chave foi "multiplication game", sendo obtidos cerca de 6.370 .000 resultados. Em ambas as pesquisas, as dez primeiras páginas resultaram em jogos que só poderiam ser aplicados com conexão à rede mundial de computadores. O que dificultaria o uso dos jogos pelo professor em laboratórios de informática sem acesso a internet.

A pesquisa realizada no SBIE resultou em oitenta e três artigos sobre jogos, cinco sobre jogos sérios e um sobre jogos de multiplicação. Dos cinco artigos relacionados à jogos sérios apenas um foi validado, o restante foi apenas desenvolvido. Já o jogo sério sobre multiplicação foi validado e avaliado.

Os resultados das pesquisas mostram que existe apenas um jogo sério destinado ao ensino de multiplicação. Assim, o professor que deseja trabalhar com jogos digitais para o desenvolvimento da automaticidade da operação de multiplicação terá dificuldades para encontrar jogos com essa finalidade. Dessa forma, o jogo Pirâmide Multiplicativa é uma ferramenta que pode ser utilizada pelo professor nas aulas de matemática, pois é um aplicativo multiplataforma que não necessita de conexão com a internet para ser inicializado. Ou seja, o jogo apresenta praticidade e faz com que o jogador aprenda a tabuada de multiplicação de maneira lúdica e prazerosa.

No questionário avaliativo os quinze licenciandos, responderam que utilizariam o jogo Pirâmide Multiplicativa durante as aulas de matemática. Os professores de 
matemática em formação afirmaram que a interface do jogo é chamativa e as cores geram motivação, interesse e vontade de jogá-lo.

Sobre a importância da utilização de jogos digitais nas aulas de matemática, os licenciandos sem exceção, responderam que os jogos digitais são uma alternativa diferenciada e eficaz para o processo de ensino-aprendizagem da tabuada. Dessa forma, o jogo Pirâmide Multiplicativa é uma ferramenta que deixa as aulas mais dinâmicas, desenvolve o raciocínio lógico e tornam as aulas de matemática mais atraentes.

De acordo com o questionário avaliativo a faixa etária para a manipulação do jogo é de 11 à 14 anos. O que confirma a intenção do jogo Pirâmide Multiplicativa de ser uma ferramenta que auxilia os estudantes do segundo ciclo do ensino fundamental em suas dificuldades referentes à tabuada.

Segundo a metodologia RETAIN, quanto à relevância, o jogo Pirâmide Multiplicativa, motiva o jogador para a aprendizagem da tabuada, o que é confirmado pelos futuros professores de matemática. Em relação à incorporação, os licenciandos consideraram a interface do jogo atrativa, sendo as instruções simples e diretas o que facilita a compreensão das mesmas. No que diz respeito a transferência, os licenciandos tiveram que recorrer a seus conhecimentos prévios sobre a tabuada. Dessa forma, utilizaram como estratégia de jogo a formação de pares que continham os resultados mais fáceis como as tabuadas dos números um, dois e três. Quanto à imersão, os licenciandos consideraram o jogo instigante e motivador, pois o cronômetro propicia uma competição e gera um sentimento de ansiedade que deixa o jogador ativo durante toda a disputa.

Para resultados mais satisfatórios, tanto para o aspecto adaptação quanto para a naturalização seriam necessárias mais aplicações do jogo. Visto que, a mudança de comportamento só ocorre quando o conhecimento é interiorizado pelo jogador e isso dependerá do ritmo de aprendizagem de cada um e da empatia do jogador pelo jogo.

Portanto, o jogo Pirâmide Multiplicativa é uma ferramenta digital para o aprendiz que já passou pelas séries iniciais do ensino fundamental, mas que esqueceu ou ainda não consolidou a tabuada da multiplicação. Assim, a Pirâmide Multiplicativa possibilita aos estudantes explorar uma ferramenta digital diferenciada daquelas utilizadas pelo professor durante as aulas de matemática.

\section{Considerações finais}

Os jogos digitais podem ser empregados como recurso facilitador da aprendizagem quando utilizados na sala de aula com intencionalidade e objetivos previamente definidos pelo professor. Dessa forma, o jogo proporciona uma aprendizagem significativa, respeitando o ritmo de aprendizagem dos educandos devido a possibilidade de retorno ao jogo quantas vezes se queira.

O jogo Pirâmide Multiplicativa contribui para a memorização da tabuada, a medida que estimula a rapidez do raciocínio, o cálculo mental e a memória visual, sendo os aprendizes motivados a aprender por intermédio da competição. A agilidade do pensamento lógico-matemático assegura aos alunos do segundo ciclo do ensino fundamental efetuar operações matemáticas rapidamente, resultando na apreensão de conteúdos matemáticos mais complexos com maior facilidade.

Devido ao tamanho do arquivo e formato multiplataforma, a Pirâmide Multiplica- 
tiva pode ser instalada e executada em qualquer sistema operacional desde os mais antigos até os de última geração. Essas configurações também possibilitam sua instalação em laptops educacionais como os utilizados no Projeto UCA (Um Computador por Aluno), visto que não necessita de acesso a internet. Além da praticidade no download e a transferência do arquivo executável para dispositivos móveis, applets, Smartphones e iPhones.

Em propostas futuras pretende-se fazer a validação do jogo Pirâmide Multiplicativa com os alunos do segundo ciclo do ensino fundamental. A partir da manipulação do jogo pelos alunos será possível melhorá-lo, implementá-lo com operações de multiplicação em outros conjuntos numéricos e disponibilizá-lo tanto para estudantes do ensino fundamental e médio, quanto para professores.

\section{Referências}

Borin, J. (2004). Jogos e resolução de problemas: uma estratégia para as aulas de Matemática. São Paulo-IME-USP.

Brasil. (1998). Ministério da Educação. Secretaria de Educação Fundamental. Parâmetros Curriculares Nacionais: Matemática. Brasília-MEC.

Cardoso, A.; Giraldello, Astride G. C.; Batista, Nalva Ap. M. (2013). Tabuada Legal: um jogo sério para o ensino de multiplicações, In: Anais do $23^{\circ}$ Simpósio Brasileiro de Informática na Educação (SBIE 2012), Campinas-SP.

Carvalho, A.; Gonçalves, H. (2003). Multiplicação e divisão: conceitos em construção, In Educação e Matemática, n. 75, p. 23-25.

Gunter, G. A.; Kenny, R. F.; Vick, E. H. (2008). Taking educational games seriously: using the RETAIN model to design endogenous fantasy into standalone educational games, In Education Tech Research Dev. 56, p. 511-537.

Kamii, C.; Anderson, C. (2003). Multiplication games: How we made and used them, In Teaching Children Mathematics, 10(3), p. 135-141.

Luciano, A. P. C.; Oliveira, L. C. (2012). Metodologia RETAIN para avaliação de sérios games aplicado ao jogo Eletrocity, In Encontro Nacional de Educação, Ciência e Tecnologia (ENECT). Disponível em: $<$ http://www.editorarealize.com.br/revistas/enect/trabalhos/Poster_838.pdf $>$.

Maluta, T. P. (2007). O Jogo nas Aulas de Matemática: Limites e Possibilidades. Universidade Federal de São Carlos, São Carlos, 71 f.

Medeiros, M. A.; Schimiguel, J. (2012). Uma Abordagem para Avaliação de Jogos Educativos: uma Ênfase no Ensino Fundamental, In: Anais do $23^{\circ}$ Simpósio Brasileiro de Informática na Educação (SBIE 2012), Rio de Janeiro-RJ.

Michael, D. R.; Chen, S. L. (2006). Serious Games: Games That Educate, Train, and Inform, In Muska \& Lipman/Premier-Trade, p. 17.

Moita, C. S. C. M. F.; Luciano, C. P. A.; Costa, T. A. (2012). Angry birds rio: interface 
CBIE-LACLO 2015

Anais do XXVI Simpósio Brasileiro de Informática na Educação (SBIE 2015)

lúdica e facilitadora do processo do ensino e da aprendizagem de conceitos matemáticos, In II Congresso Internacional TIC e Educação, p. 3079-3090.

Moura, P. C.; Viamonte, A. J. Jogos Matemáticos como Recurso Didático, Disponível em: <http://www.apm.pt/files/_CO_Moura_Viamonte_4a4de07e84113.pdf >.

Otsuka, J. L. et al. (2012). Desenvolvimento de Jogos Educacionais Abertos, In: Anais dos Workshops do Congresso Brasileiro de Informática na Educação, Rio de Janeiro-RJ.

Skovsmose, O. (2000). Cenários para investigação, In Boletim de Educação Matemática, Rio Claro, n. 14, p. 66-91. 